This is the post-peer reviewed final draft version of the following article: Heeks, R. \& Kanashiro, L.L.. "Telecentres in mountain regions: a Peruvian case study of the impact of information and communication technologies on remoteness and exclusion", Journal of Mountain Science, 6(4), 320-330, 2009, which has been published in final form at: http://link.springer.com/article/10.1007\%2Fs11629-009$\underline{1070-y}$

\title{
Telecentres in Mountain Regions \\ A Peruvian Case Study of the Impact of Information and Communication Technologies on Remoteness and Exclusion
}

\author{
Richard Heeks* and Laura León Kanashiro \\ Centre for Development Informatics, Arthur Lewis Building, University of \\ Manchester, Manchester, M13 9PL, UK \\ richard.heeks@manchester.ac.uk; leon.laura@gmail.com
}

*Corresponding author

Communities in developing country mountain areas, in part due to their remoteness, find themselves excluded from social, political and economic systems; and excluded from access to resources. This paper researches the impact on remoteness and exclusion of information and communication technologies (ICTs). It utilises two models - the resource movement framework, and the "information chain" - to analyse a telecentre in one district of mountainous Huancavelica, Peru's poorest region, set in the high Andes. It finds ICTs enabling new and positive resource flows for the two key user groups: teenaged school students and young farmers. These help to maintain social networks. They also support information searches that have improved agricultural practice where other information chain resources have been available. But non-use and ineffective use of the telecentre are found where information chain resources are lacking. ICTs have some impact on intangible elements of remoteness. In this particular example, they also offer access to some previously-excluded resources. But they have not really addressed the systematic exclusions faced by mountain communities. And they so far appear to be a technology of inequality; favouring those residents who begin with better resource endowments. The paper concludes by offering some recommendations for mountain ICT project practice.

Keywords: exclusion; telecentres; information and communication technologies (ICTs); new technologies; Andes; Peru 


\section{Introduction}

Information and communication technologies (ICTs) bring with them a promise of addressing developmental problems of mountain regions. This paper investigates that promise, asking what role ICTs can play in overcoming remoteness and exclusion.

It first identifies two conceptual frameworks - resource movement and "information chain" - that can help understand this question. It then explains research that was conducted on one telecentre based in Pazos, Peru. Findings on use and non-use of the telecentre are explained, and the final section of the paper draws some conclusions and recommendations.

\section{Understanding Mountain Regions and ICTs}

A number of the problems faced by mountain communities can be laid at the door of disconnection and exclusion (Panos 2002). We can characterise exclusion in a number of different ways. For those living in mountain regions, there are various forms of systemic exclusion: that is, exclusions from the key systems of development. These would include:

- Social exclusion: e.g. from public service systems such as the health system and the education system (Carver 1999).

- Political exclusion: e.g. from political systems including political parties, from political agendas, and from policy priorities and the rights of citizenship (Altamirano et al 2004).

- Economic exclusion: e.g. from economic value chains, both input systems such as banking and credit; and from output systems such as traders and customers (Lightfoot et al 2008).

Underlying all these forms of exclusion is a foundation of resource exclusion. We can understand this as an exclusion from the six resource capitals that make up livelihood assets (DFID 1999):

- Human: information, knowledge, health, skills

- Natural: land, water, forest

- Financial: money, financial assets

- Physical: transport, housing, energy, raw materials, tools, equipment

- Social: networks, relationships, group membership

- Political: power, status

For the poor in mountain regions, we need to add in one further factor: their remoteness. Their physical remoteness - their distance from main centres of population and their high/steep landscape - means, for example, that physical infrastructure (transport, energy, telephony, etc) does not reach them, or that it only does so intermittently, or at high cost. This in turn makes it either impossible or high cost to access the systems and resources listed under the two exclusions above. Physical remoteness means the same thing for the socio-economic infrastructure: health centres, schools, markets, government offices, and so on are absent in mountain areas or cost more to access. Mountain communities are also remote in less physical ways: from centres of knowledge, political power, economic activity, etc; indicating 
the overlapping and reinforcing nature of systemic exclusion, resource exclusion and remoteness.

\subsection{Conceptualising the Role of ICTs}

Because exclusion means disconnection from systems and resources, there has been an ongoing interest in what "technologies of connection" have to offer mountain communities; particularly what they have to offer to resource exclusion by their impact in reducing remoteness. One such technology of connection is information and communication technology.

Seeing it as technology of connection, we can understand ICT in terms of the resources that it carries along that connection. In this case, the resource will be data, and as with more general discussions about mountain communities and resources, we can understand the impact both in terms of resources that are brought into mountain areas, and resources that are taken out of mountain areas. Reviewing past literature, we find that some views on this movement of resources regard it as positive for mountain communities; others view it as a negative outcome.

We can therefore summarise past views on the impact of ICTs on mountain communities using a "resource movement framework", as shown in Table 1, which combines the type of resource movement with the nature of the view expressed.

\begin{tabular}{|c|c|c|}
\hline & Resources Brought In & Resources Taken Out \\
\hline \multirow[t]{2}{*}{ Positive } & $\begin{array}{l}\text { Health information and online } \\
\text { education (Helmersen 2001) }\end{array}$ & $\begin{array}{l}\text { Promotion of area to tourists, and } \\
\text { contact with distant government } \\
\text { officials (Panos 2002) }\end{array}$ \\
\hline & $\begin{array}{l}\text { Information on market prices } \\
\text { leading to ... }\end{array}$ & $\begin{array}{l}\text {... greater sales of agricultural } \\
\text { produce in external markets } \\
\text { (Lightfoot et al 2008) }\end{array}$ \\
\hline \multirow[t]{2}{*}{ Negative } & $\begin{array}{l}\text { Downloading of pornography } \\
\text { (Montgomery 2002) }\end{array}$ & \\
\hline & $\begin{array}{l}\text { Information on lifestyles in urban } \\
\text { areas leading to ... }\end{array}$ & $\begin{array}{l}\text {.. loss of local youth through out- } \\
\text { migration (Byers et al 1999) }\end{array}$ \\
\hline
\end{tabular}

Table 1: Views on Resource Movement Impact of ICT Connections to Mountain Communities

However, some of these views have been based on conjecture rather than evidence and there is a recognised need for more impact studies of ICTs in mountain areas (Kohler et al 2002). With a specific view to the impact of ICTs on the lives of the poor in mountain regions, we can model these into a framework to analyse exclusion: the "information chain", as shown in Figure 1.

The model is a development of Heeks (2005) that has three main origins. It draws from the information systems discipline, which has analysed how raw data comes to be transformed into organisational value (Ward \& Peppard 2002). It draws from development studies' sustainable livelihoods framework - used already above in discussing resource exclusion - to incorporate the notion that resources are a key 
component in producing development results (DFID 1999). And it draws from ideas about ICT literacy that move beyond the basic notions of "computer skills"

(Warschauer 2002).

It also fits with literature on mountain communities and connectivity (e.g. Aitken 2002, Karumuna 2004) which suggests that the impact of any type of connectivity is more about what is carried by the connection than the nature of the connection; and that connectivity requires complementary inputs to be effective for mountain communities.

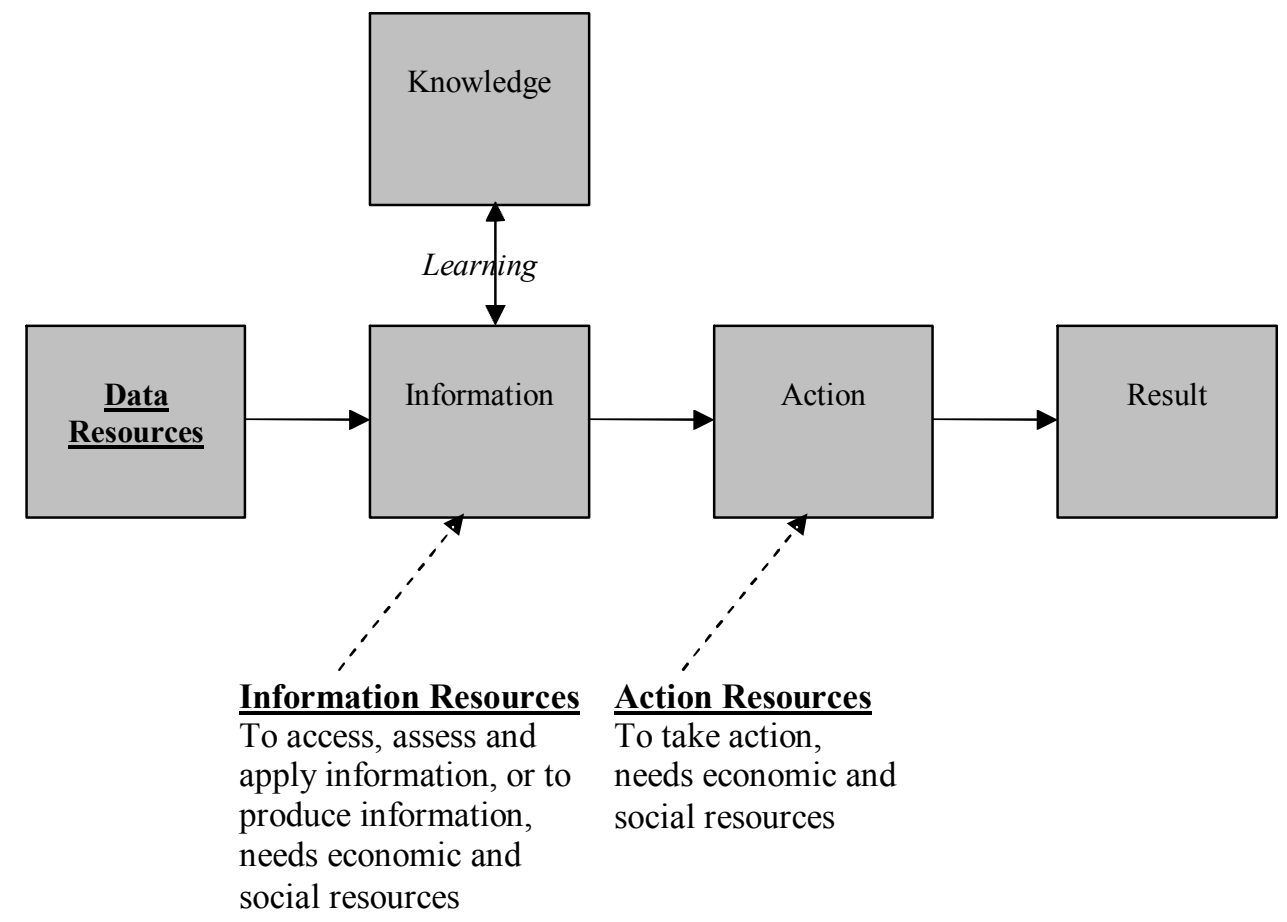

Figure 1: The Information Chain

ICTs just process and communicate digital data. The information chain is a reminder that more than just technology is required in order for ICTs to create development results in mountain communities. Relevant, appropriately-presented data must be available. Community residents must have the skills, knowledge and motivation to access that data; to assess its qualities; and to apply it to their particular needs. To actually deliver results, action resources are needed: money and raw materials; skills to undertake the action; power and motivation to make it happen; social and business contacts to create the desired result. In other cases, the information and action resources are those required in order for community members to create online information that other communities, or those outside mountain areas can use.

In all, then, we can say that the arrival of ICTs in a mountain community has little or no impact of itself. To impact development, a raft of complementary resources must be present. Figure 1 categorises these in terms of the links in the chain as data, information, and action resources. Or we could categorise these resources as:

- Tangible: technology, money, raw materials.

- Semi-tangible: data, knowledge, skills, time, contacts. 
- Intangible: information, power, motivation.

Having conceptualised the relation between ICTs and mountain development, we now describe the research that applied these models to use of ICTs in one particular mountain location.

\section{Research Context, Setting and Methods}

The chosen location for this research was Peru. Peru was selected because it is very mountainous and because the rapid growth of ICTs in the country has been uneven, leaving rural - including mountain - areas relatively poorly served (INEI 2006). One reaction has been initiatives seeking to overcome the digital divide, including ERTIC (Establecimientos Rurales de Tecnologías de la Información y Comunicación: rural ICT establishments).

ERTIC focused on Huancavelica region, located to the south-east of the capital, Lima (see Figure 2). Huancavelica lies fully within the Andean highlands and is Peru's poorest region, with more than $85 \%$ of the population living on less than US $\$ 1$ per day (Escobal \& Torero 2003, INEI 2008). Implemented in 2006, ERTIC set up telecentres - five PCs, server, printer, scanner, and satellite Internet connection - in ten districts of Huancavelica, each based in an earlier-created small public library space. 


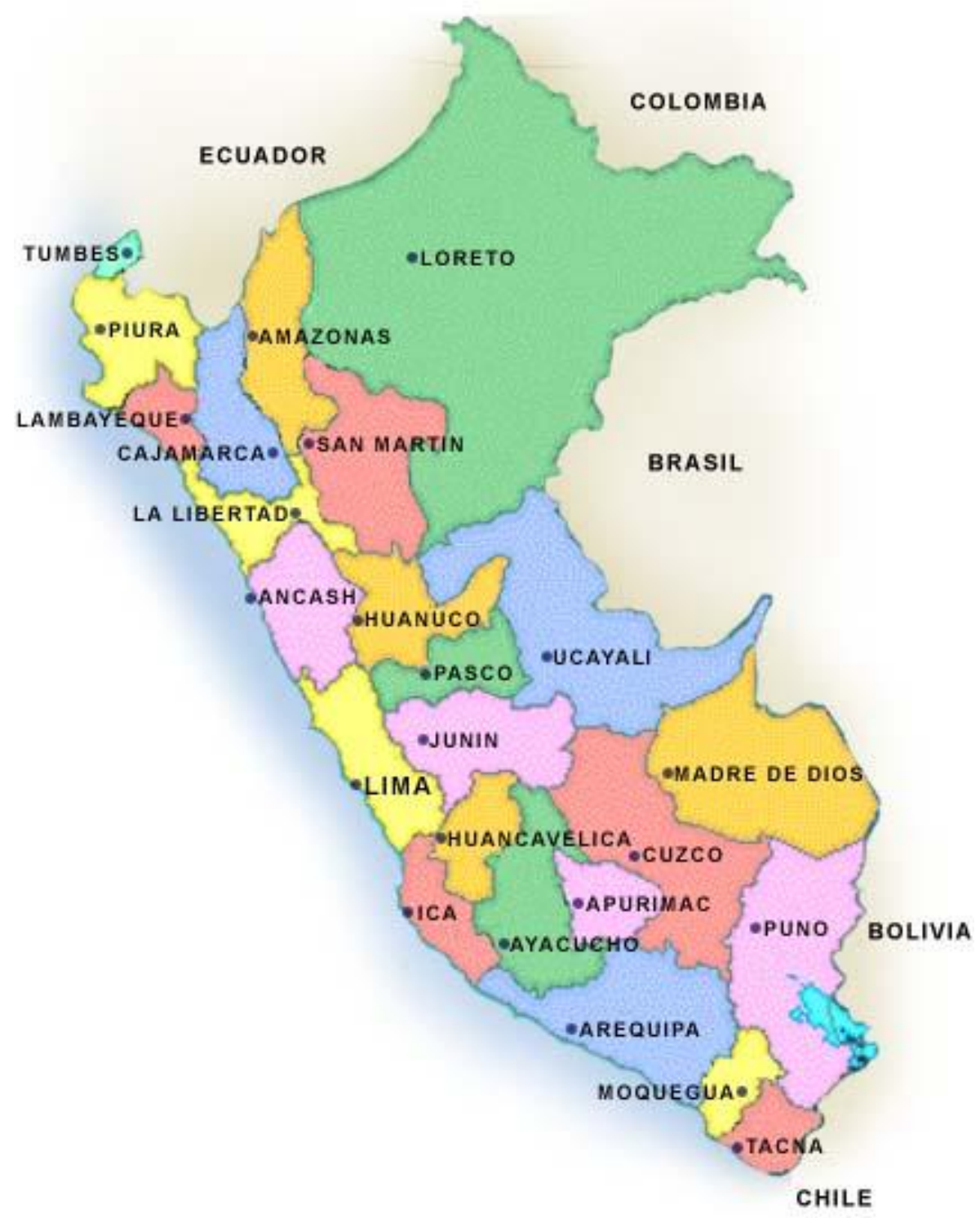

Source: peru.com (2007)

Figure 2: Peru and its Regions

The chosen focus for this research is the telecentre installed in Pazos district, which lies at the northern end of Huancavelica region. The district's main town - also called Pazos (see Figure 3) - lies at 3,840m though the district overall encompasses 13 other smaller villages between $2,600 \mathrm{~m}$ and $4,400 \mathrm{~m}$, with a total population of just under 8,000 people (ERTIC 2007). 


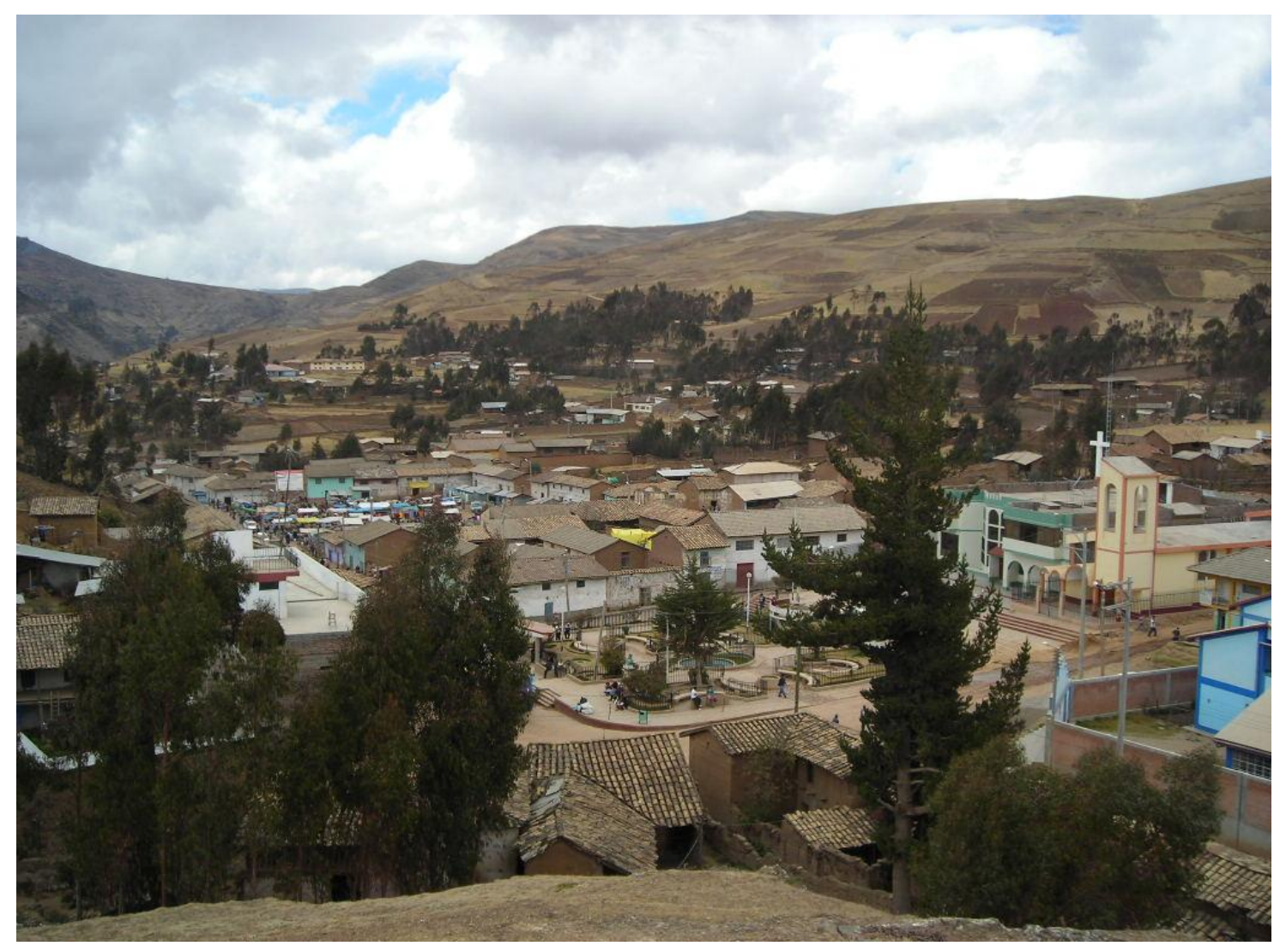

Figure 3: Pazos Town

In reviewing Pazos as a mountain location in a developing country, we can say that it is typical in many respects such as altitude and poverty. It is typical in relying on agriculture: mainly subsistence farming using manual labour; particularly growing potatoes though with some limited livestock (mainly sheep), dairy and textile production. Any surpluses tend to be sold in the weekly market in Pazos town. And Pazos is also typical in the relatively poor state of some of its infrastructure: the condition of school buildings, equipment and materials is generally reported as poor; only $10 \%$ of roads are formally maintained; there is no mobile phone coverage, and the whole district has just eight public phones offering a poor quality service.

In other ways, though, Pazos does not represent an extreme of mountain exclusion. It has sixteen primary and four secondary schools, plus an outreach centre for the provincial Agricultural Technical Institute (ATI). It has a health centre and four clinics. $87 \%$ of the population has access to electricity and $80 \%$ are literate. And it is only one hour by motorised transport from Huancayo (the capital of neighbouring Junin region, with more than 300,000 inhabitants). This profile is not unexpected for current research on ICTs in mountain areas: the world's remotest, most-excluded areas are not yet connected.

In order to research the Pazos telecentre, a three-month study was conducted in 2007; just over one year after the telecentre's initiation. This looked at the two primary user groups of the telecentre - secondary school students and young peasant farmers - but also covered non-users as well. Three research methods were used: 
- Observation of ICT usage conducted within the telecentre. Five of these observational sessions were open: just recording whatever usage was undertaken. One session was directed: testing out the abilities of users to complete a set of ICT tasks.

- Four focus group sessions conducted with small numbers of primary user group members to talk about their usage of ICTs.

- Twenty-nine individual interviews. The interviews covered both users and nonusers of the telecentre; based both in Pazos town and in outlying villages.

\section{Telecentre Users, Usage and Non-Users in Pazos}

The ERTIC project's telecentres were intended to drive cultural, economic and social development (INICTEL 2006). The project planning document notably leaves unspoken how exactly this development is to be achieved via use of ICTs. However, in implementation, the project tried to shape ICT usage towards its intended goals.

The ERTIC telecentres charged US $\$ 0.30$ per hour for Internet access (about one-third of average daily income for one hour's use, equivalent to the cost of a meal) but farmers looking for agricultural information were allowed one hour free. Access to pornographic websites was prohibited, as was the playing of computer games. Internet searches for educational, commercial or "professional" purposes were, by contrast, deemed to be high priority (ibid.).

Two further elements were incorporated with the intention of enhancing the developmental role of the telecentres.

The first was training. The two local telecentre managers were given technical training on topics like Linux, network management, and web design. But they were also given training in user relations, such as promotion of Internet use. The telecentre managers in turn gave training to potential users; both general IT training on computing basics and document production, but also an awareness-raising exercise on potentially-interesting uses of the Internet such as finding cooking recipes, or researching domestic violence. In Pazos, during the six-month initial training period, 547 people were trained (about 7\% of the district's population).

The second was local content production for the ERTIC project web portal. One element of this was quasi-bottom-up: a network of local "correspondents" was created to produce news for the web portal. The other element was top-down. INICTEL produced videos for tourism promotion and agricultural training, and set up Plataforma Rural de Huancavelica (Huancavelica Rural Platform). The latter was a separate web portal through which INICTEL intended to provide distance learning materials (including its videos) on improving agricultural practices in crop and livestock farming; a virtual library of documents on agriculture and post-farm production; and a commerce portal through which farmers could offer specialist produce, handicrafts and services.

Taken together, these elements of the ERTIC project provided a set of key resources, each of which addresses aspects of the resource exclusion of populations in mountain regions: 
- Technology: specifically technology intended to leapfrog geography to move from a situation of physical remoteness to virtual connectedness.

- Skills: in making use of the technology.

- Information: about key aspects of the livelihoods of mountain region inhabitants; particularly upland agriculture.

In addition, through the commerce portal, there was potential for inclusion in previously-inaccessible markets.

From this foundation, what actual uses of the telecentre were found?

As noted above, two main user groups were identified from the observational work: secondary school students (see Figure 4), and young peasant farmers. For both groups, the project had provided information chain resources in practice: beyond the technology, interviewees mentioned the value of the skills and knowledge they had gained from the telecentre managers. It emerged, though, that this built on a preexisting foundation: almost all users had already used one of the cabinas publicas in nearby Huancayo (usually encouraged by a friend or relative in the city who took them to look at the Internet or to set up an email account), and received some ICT introduction in their school or college.

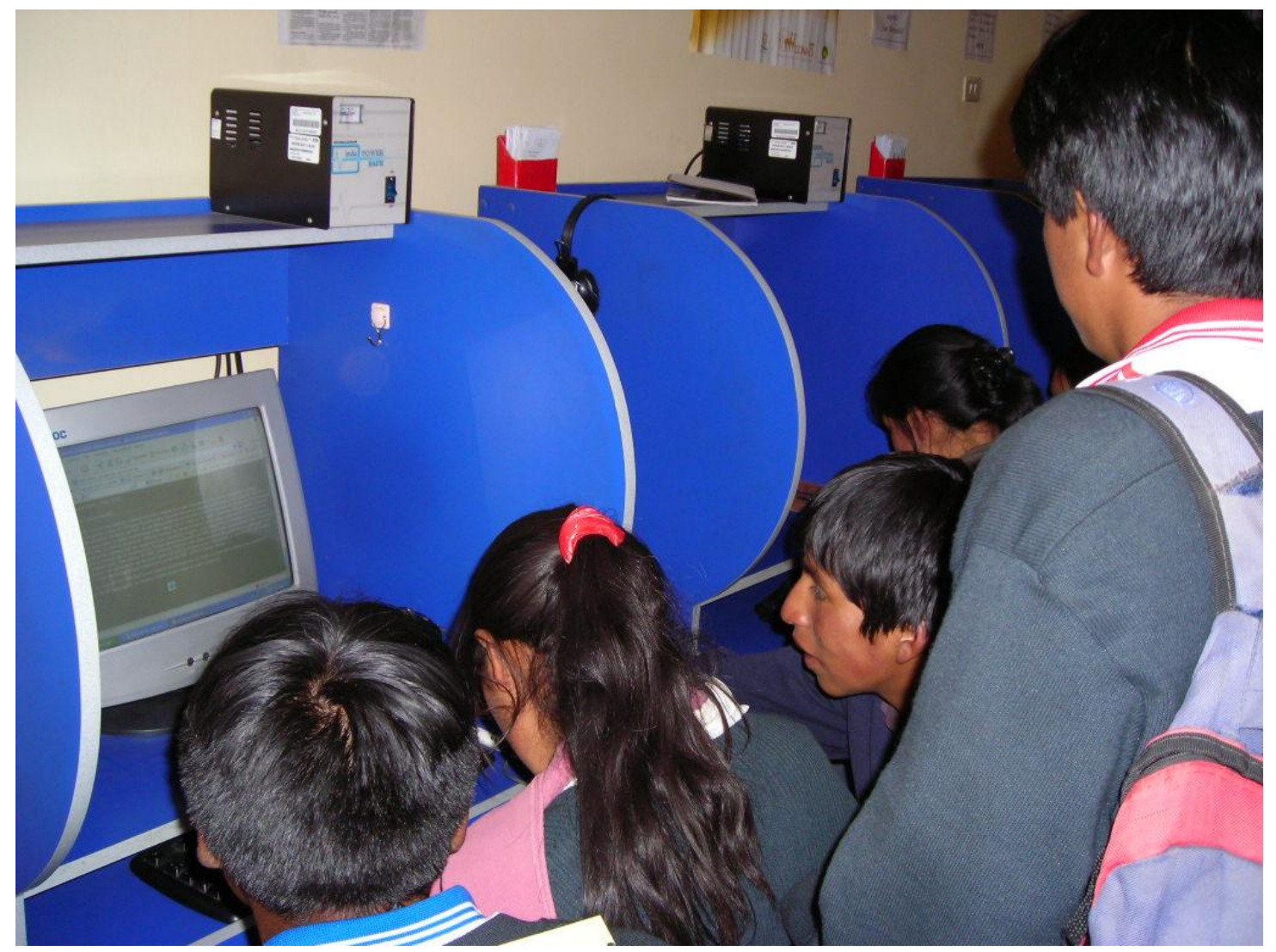

Figure 4: Teenaged Telecentre Users

The teenaged school students (aged 15-17, both boys and girls) who lived near to the telecentre were regular users, going two or three times per week for around one hour a day from $5 \mathrm{pm}$. For them the physical space of the telecentre was also a social space: 
one would find a group of six or seven together gathered around one or two computer users; typically discussing what they were seeing on screen but also socialising more generally with each other. This is, therefore, collective consumption of the new medium, and one can see that collective as building its own information chain resources - particularly ICT skills and knowledge, and knowledge about accessing and assessing data. Less analytically, it was also notable that the telecentre provided a space for teenagers of the opposite sex to meet together, and that all activities were undertaken to the constant beat of reggaeton music.

The farmers represented a smaller group. They were aged in their 20s, and were all either students or graduates of the Agricultural Technical Institute. Usage was focused on Saturday when the farmers came into Pazos town for market day. Like the teenagers, farmers would often talk together about their computer-based activity.

On the basis of observation, two main categories of use - social and informational can be seen. We will also comment on two other issues: creation of local content, and non-use.

\subsection{Social Use}

The teenagers' telecentre usage centred on, and was motivated by, communicating with distant relatives or friends who had migrated to live in cities such as Huancayo, Huancavelica or Lima. The same was true - though to a lesser extent - of the young farmers. They used email or MSN (Windows Live) Messenger and the main information flow was outward.. For example, they would inform the migrant "pazinos" about village news; both more formal news of the births, deaths and marriages variety, and less formal news that fell more into the category of gossip. They would also send messages about events such as local festivals that the migrants could return to attend. Local users' skills in these applications were relatively deep, including the ability to use emoticons, attach pictures, and make use of the telecentre webcam. The fact that migrants did, indeed, return for the events suggests that this information chain was working.

One stereotype of ICT usage is that it reinforces existing social networks for poor users, rather than extending those networks (e.g. Ureta 2008). This did appear true of the farmers but it was not the whole story in Pazos. Almost all of the teenagers interviewed would chat online with unknown respondents who in some mysterious way just "appeared" on their Messenger contact lists. Although they assumed these to be teenagers, they were also well aware that people could make up identities, and about the dangers of meeting up; something their contacts sometimes proposed:

"[My contact $]$ he is from Huancayo city; he says that, but I do not know. He has been asking me several times to go out in Huancayo, I have accepted but I have never really gone ... I do not know him, how might he be?" (Teenager, Pazos, female user)

Mainly through discussions with their real friends, this group had therefore developed the information chain resources necessary to make a relatively discriminating assessment of this particular data. 


\subsection{Information Searches}

Farmers' telecentre usage was dominated by searches related to agriculture: for information on new products, technologies and techniques; for information on events and training courses; and for information on markets and prices. Their searches were often focused on sites from public sector organisations like the National Agricultural Research Institute and the National Agriculture University. Their searches notably never involved the project's own Huancavelica Rural Platform. (This was perhaps not surprising given that the Platform - http://pallasca2.inictel.net - does not seem to have lived up to its ambitions: at the time of writing, it seemed that no new content had been added to most parts more than one year, and content was very limited; only the section on educational courses still appeared active.)

Slightly strangely, the ERTIC project did not include training in Internet information searches, but the telecentre managers had given enough individual support to get users started. There had also been encouragement from the educational institutions. Those few school students who used the web to find information for their homework did so in a couple of subjects where their teacher had specifically referred them to webbased sources. The same was true of the Agricultural Technical Institute - lecturers had specifically given assignments motivating the student-farmers to make use of the web.

Through experience and/or training, the farmers had a good understanding of the limitations of web-based, externally-sourced information. In part, this was encouraged by the experimental and evidence-based approach taught by the ATI:

"For me, the results [from a web search] are given only in the field. In some cases it worked and in other cases it did not. We cannot know from the website because they are from another 'system'". (Young farmer, Tongos, male user)

"I also use it to be updated: livestock, pork and guinea pig farming in other places is different. Then we talk to other technicians to discuss if it can be implemented here in this area, because if we plant here seeds from other places, maybe it will not work." (Young farmer, Pazos, male user)

Farmers therefore made use of their own and others' knowledge in order to run the first steps of the information chain effectively. In some cases, the "others" used are farmers in Pazos. In other cases, though, these are colleagues in different regions of Peru met during the internship in a different agriculture institute required as part of agricultural technical training. The farmers all used email and Messenger to maintain the combined social and productive value of this contact network.

As an example of this in action, one of the farmers from Aymará village needed help to protect his crop from weevils. He got in touch with a technical contact at a distant agricultural research centre who suggested use of plastic barriers. He then searched the web for further information. Having motivation, money, and the ability to source the plastic, he then applied it to a portion of his field, later adopting it for his whole crop once it had been shown to work. 
Farmers also integrated the knowledge they gained from their internships with webbased information. Two had been in Cuzco (a region some distance from Pazos but in the mountains) where they saw farmers growing crops traditionally regarded as coastal like tomatoes, melons and pickles. Wondering if this would be possible in Pazos, they used web searches to find out about methods of cultivation, soil types, pests, etc; applying their collective knowledge in order to assess the validity and application of this data. Having - like the previous farmer - the motivation, money and ability to source necessary inputs, they set up a greenhouse which duly produced a good crop, and motivated other farmers to follow suit.

In other cases, though, farmers were not able to make effective use of the information they found. Some had found information about potato wholesalers to whom, in theory, they might sell their crops. They were interested to take this further but they lacked the resources to produce a crop of a quality high-enough to meet wholesaler requirements. In particular, they lacked some of the raw materials such as new kinds of seed potatoes and insecticide; they lacked some of the skills and knowledge that the "more professional" approach to potato growing would require; and they lacked knowledge about where to obtain these resources. Even had they overcome these particular resources barriers, they probably lacked the resources (particularly skills, knowledge and confidence) to set up and fulfil contracts with wholesalers. As a result, this new information did not lead to a developmental result.

\subsection{Local Content Creation}

As noted above, local content creation was one of the aims of the ERTIC project and also one of the interests of local users:

"Yes, I would like to learn [to publish information] in order to put information about our school, how it is, what we are working on ... this is to be seen by other schools in Huancavelica." (Teenager, Pazos, female user)

"I would like to have my reports about agriculture and livestock farming to be seen by others and help them." (Young farmer, Tongos, male user)

These users no doubt had the information and knowledge resources necessary to begin the information chain. As their statements suggest, they also had the motivation. But the chain did not materialise because users here were not involved in the "correspondents" project; nor did they receive any training on how to publish local content. Thus none of those interviewed knew how to create and publish their own data.

As a result, the farmers' aspiration (and the project's promise) of finding new markets for their produce had not been achieved:

"The idea was that the Internet would solve problems of commerce and trade ... they said our products would be offered [online] but ... it has been a year and nothing has been solved." (Young farmer, Mullaca, male user)

(As another result, local content for the ERTIC web portal was provided only by telecentre staff, not by ordinary users, and it could only be uploaded by INICTEL staff in Lima, not by anyone in the telecentres.) 


\subsection{Non-Use}

Non-users were included as interviewees. They did not lack awareness: all interviewees, whether users or not, were aware of the telecentre and had some idea about use of the Internet for communication and information. Indeed, most had been trained as part of the project.

Nor did non-users lack general motivation: all the farmers appeared equally interested in improving their crop yields, increasing their incomes, and introducing new technologies. Most - user and non-user alike - were enrolled in a project that was aiming to reduce dependency on potato cultivation.

However, non-users did lack a number of important information chain resources. Even if trained, their IT skills had atrophied since training, contrasting with the users who had steadily built on the skills foundation provided by the course. The absence of Internet information search skills training had left an important gap, and non-users lacked the social or educational institution networks that had helped fill this gap for others. Hence, alongside the IT skills, they also lacked information skills, e.g. the ability to find information online and then filter it by assessing what had good data quality and what did not.

More fundamentally, non-users were found to be less proficient in literacy in Spanish than the user population. The Pazos population overall is bilingual in spoken Spanish and Quechua. Most non-users did not come from the $20 \%$ of the population that was illiterate in Spanish, but they were generally not confident in reading or writing Spanish; yet this was the language in which all potentially-relevant web sites were presented. This, in turn, was mutually reinforcing with their expressed preference for face-to-face communication.

They therefore found the web to be too text-based, too static, and insufficiently interactive. They also wanted a practical demonstration of results before they would be willing to change their agricultural practices. We could put this down to issues of risk aversion, but it more seemed to reflect a distinction between the concrete and the abstract. Users were willing and able to take the abstract - data found on the Internet - and turn it into the concrete through experimentation. Non-users were not.

This also seemed to relate to self-efficacy: "the belief that one is capable of performing in a certain manner to attain certain goals" (Heeks 2009). Low selfefficacy has been particularly noted with women in ICT-for-development projects, and the same was found here - a belief among some of the female farmers that they were not good at using the telecentre:

"I do not know how does it work and I am embarrassed because sometimes I do not understand and I need them to repeat to me." (Older farmer, Pazos, female non-user)

Beyond gender, there were other demographic aspects to non-use of the telecentre. For example, older community members were hardly present. In part, this reflected ERTIC project goals, which saw beneficiaries as those "aged 39 or less" (MEF 2005). Older members lacked some of the basic information chain resources, such as IT skills, appropriate knowledge, and motivation. 
There were also geographic aspects of non-use, with some negative relationship between distance from telecentre and level of use. For the school students, this was often a matter of time/opportunity - they had to walk some distance to and from their homes, and that precluded them attending the telecentre. As a result, despite motivation, they also lacked the kind of IT skills and confidence that their more proximal classmates had picked up. By contrast, some farmers from outlying districts did use the telecentre because they came by it every Saturday.

Finally, there were aspects to non-use that were user-independent because they related to the data resources that begin the information chain. We can identify five main qualities of data resources, under the CARTA acronym: completeness, accuracy, relevance, timeliness, and appropriateness of presentation (Heeks 2006). In two ways, data was qualitatively deficient and so led to non-use in specific circumstances.

Sometimes, farmers were unable to find relevant data. For example, one of the farmers had tried searching for data relevant to local needs of growing artichokes, and marketing guinea pigs. He had been unable to find such data and, more generally, project staff reported this as a problem suggesting it was an issue of data availability rather than deficient search skills.

In other cases, data was not appropriately presented. There were technical databases of agricultural information, for example about soil composition and its relation to yields, that farmers were unable to use. Other information could be accessed but was in such technical language that it could not be understood. Again, project managers corroborated the problem, suggesting it should be seen as a data not user issue.

\section{Analysis, Conclusions and Recommendations}

Pazos does not get physically closer to anywhere thanks to a telecentre. But it does get virtually closer and this helps overcome some constraints of geography. It has helped Pazos residents be and feel more connected with distant social contacts. It has helped Pazos residents be and feel more connected with distant sources of information. While physical remoteness may remain, then, virtual and psychological remoteness are reduced.

But this is not the death of geography. In other ways, the physicality of space keeps asserting itself. The telecentre provides a physical space for socialisation, and its levels of usage and its perceived value derive in part from this. Distance to the telecentre is a partial determinant of use and non-use. And the proximity of a sizeable city, Huancayo, has affected telecentre usage; quite possibly in ways that one may not find in more remote mountain locations.

Applying the resource movement framework, current evidence falls mainly into the positive category. New information brought into the community had led to improvements in agricultural practices. Information flowing out (or, more accurately, exchanged to and fro) had helped to cement social/productive contacts. The only question mark lay over some of the new contacts that teenagers were making. 
Applying the information chain model, we see effective use of ICTs being founded on the presence of necessary information chain resources.

In terms of resource exclusion, then, the ERTIC project overall has led residents in this mountain community to access some resources from which they were previously excluded: data, skills, knowledge, technology. Set against this, though, adding a telecentre in this way notably fails to provide access to other important resources; such as the raw materials, skills, knowledge and confidence we found underlying the non-functioning of some information chains.

We can also see signs of the reproduction of both inclusion and exclusion. Many key information chain resources are built thanks to inclusion in external systems: basic IT skills and confidence from visits to the nearby city; knowledge and contacts from enrolment in the Agricultural Technical Institute. These in turn enable more effective use of ICTs when the technology arrives in the mountain community. And that more effective use reinforces or enables further inclusion: supporting geographicallydispersed contacts and networks; providing access to distant information. By contrast, those who began as more excluded - older inhabitants, students living in the poorer districts further from the telecentre, perhaps female farmers - found it harder to make effective use of ICTs, and this reinforced their exclusion.

Looking more systemically at the impact of ICTs on exclusions, we have seen an inclusion in circuits of information and knowledge about economic activity. But we have not yet seen inclusion in new economic institutional systems, such as distant markets. Nor did we yet find any evidence of inclusion in formal social or political systems.

What, finally, about inclusion in less formal social systems? The general message seems to be one of continued more than new inclusion. All mountain community users employed ICTs to reinforce their existing social networks. Relatively few seemed to be expanding their social networks, so far with uncertain results.

More generally, we can see the important interaction between social and digital networks. Just as ICTs support social networks, so social networks support use of ICTs. We are thus far from any notion of the atomised individual in cyberspace. The ICT users in this mountain community are surrounded both virtually and physically by human beings: the friends and relatives who introduce the Internet; the telecentre managers who provide skills, knowledge and support; the friends who group around and discuss when they use a PC; the contacts who help in locating, assessing and applying online agricultural information. Because of this, those who begin with stronger social networks are likely to derive more benefits from the insertion of ICTs into a mountain community, and to strengthen those networks further through use of ICTs.

Putting these last few points another way, those who already have some of the necessary information chain resources - resources which social networks clearly help to provide - will of course gain more from the arrival of ICTs in mountain communities than those who lack such resources. We therefore have the basis for the entirely-predictable finding that ICTs will exacerbate inequalities within mountain communities. 


\subsection{Recommendations for Practice}

The analysis here is firstly an argument for an "info-centric" perspective on the use of ICTs in mountain areas. Unless project members understand the role that data (when turned into information) can and could play in these communities, they will have no strategic direction for their projects. This understanding could go as far as a formal information needs and mapping exercise prior to the ICT project.

Mountain ICT projects should be "chain-centric". They should look at the developmental results the project is seeking to deliver, and then track through the key information chain resources required to turn the ICT-borne data into those results. They should then analyse where those chain resources would come from; and seek to facilitate their supply.

Projects can facilitate this supply directly. But they can also be "socio-centric"; recognising - as in the ERTIC project - that new chain resources are mainly provided by individuals' social contact networks. Effective mountain ICT projects therefore build in the formation of new social contacts that can in turn provide new resources (e.g. Lightfoot et al 2008).

Finally, we recommend that mountain ICT projects are "econo-centric". Social, welfare and political uses of ICTs are important. But arguably economic uses are the most important, and the one that mountain ICT projects should attend to the most. The no. 1 difference between the poor and everyone else is - obviously! - money; so finding ways to help users earn more money will be a top priority. Sustainability of projects often requires that they generate income, and users are most likely to pay where they see a direct, positive financial impact.

\subsection{Future Research}

We must be a little measured about conclusions drawn from one relatively-young mountain ICT project in one district; a district that is only partly-typical of mountain areas. We call for more research - particularly well-conceptualised research - on good practices and impacts of such projects. Such research can build on the two frameworks presented here: the resource movement framework, and the information chain model. Work using other impact assessment frameworks would also be welcome. 


\section{Acknowledgements}

The research reported here was accomplished via a grant from the International Development Research Centre, Canada, and Microsoft Corporation; and with the support of the Seminario Permanente de Investigacion Agraria (Permanent Seminar on Agricultural Research), SEPIA.

\section{References}

Aitken, H. 2002).Bridging the mountainous divide: a case for ICTs for mountain women. Mountain Research and Development, 22(3): 225-229.

Altamirano, T., Copestake, J., Figueroa, A. and Wright-Revolledo, K. 2004. Universal and local understanding of poverty in Peru. Global Social Policy, 4(3): 313-336.

Byers, A., Gilligan, N., Golston, S., and Linville, R. 1999. Mountains: a global resource. Social Education, Sept:281-296.

Carver, R. 1999. The Accursed Mountains: Journeys in Albania. London, UK: Flamingo.

DFID. 1999. Sustainable Livelihood Guidance Sheet Section 2. London, UK: Department for International Development.

ERTIC. 2007. Bienvenidos al Distrito de Pazos. Lima, Peru: Establecimientos Rurales de Tecnologías de la Información y Comunicación.

http://ertic.inictel.net/web3/distrito/index.shtml?apc=Qq11-\&s=I\&e=q (in Spanish)

Escobal, J. and Torero, M. 2003. Adverse Geography and Differences in Welfare in Peru, WIDER Discussion Paper no.73. Helsinki, Finland: World Institute for Development Economics Research.

Heeks, R.B. 2005. Foundation of ICTs in Development: The Information Chain, eDevelopment Briefing no.3. Manchester, UK: Centre for Development Informatics, University of Manchester.

http://www.sed.manchester.ac.uk/idpm/research/publications/wp/di/short/DIGBriefin g3Chain.pdf

Heeks, R.B. 2006. Implementing and Managing eGovernment. London, UK: Sage.

Heeks, R.B. 2009. Participatory design problems in ICT4D, ict4dblog, 23 Jan http://ict4dblog.wordpress.com/2009/01/23/participatory-design-problems-in-ict4dthe-low-self-efficacy-issue/

Helmersen, P. 2002. Re: ICTs in mountains, contribution to APMN e-conference on The Intervention on Technologies in Mountain Areas, 14 March

INEI. 2006. Las Tecnologías de Información y Comunicación en los Hogares: Agosto-Octubre 2006. Lima, Peru: Instituto Nacional de Estadística e Informática. (in Spanish) 
INEI. 2008. La Pobreza en el Perú en el Año 2007. Lima, Peru: Instituto Nacional de Estadística e Informática.

http://censos.inei.gob.pe/documentosPublicos/Informe_Tecnico_Pobreza2007.pdf (in Spanish)

INICTEL. 2006. Reglamento de Funcionamiento del Establecimiento Rural de Tecnologías de Información y Comunicación (ERTIC), internal document. Lima, Peru: Instituto Nacional de Investigación y Capacitación de Telecomunicaciones. (in Spanish)

Karumuna, B.L. 2004. The challenge of providing access to the Uluguru Mountains, Morogoro Region, Tanzania. Mountain Research and Development, 24(4): 284-287.

Kohler, T., Hurni, H., Wiesmann, U., and Kläy, A. 2002. Mountain Infrastructure: Access, Communication, and Energy, Background paper for Bishkek Global Mountain Summit. Kathmandu, Nepal: Mountain Forum.

Lightfoot, C., Gillman, H., Schueurmeier, U., and Nyimbo, V. 2008. The First Mile Project in Tanzania. Mountain Research and Development, 28(1):13-17.

MEF. 2005. Formato SNIP-03. Lima, Peru: Banco de Proyectos, Ministerio de Economía y Finanzas.

http://ofi.mef.gob.pe/bp/ConsultarPIP/frmConsultarPIP.asp?accion=consultar\&txtCod igo $=16772$ (in Spanish)

Montgomery, L. 2002. Re: ICTs in mountains, contribution to APMN e-conference on The Intervention on Technologies in Mountain Areas, 10 March.

Panos. 2002. High Stakes. London, UK: Panos Institute.

peru.com. 2007. Information by Regions. Lima, Peru: peru.com. http://www.peru.com/PERUINFO/ingles/info_dptos/in_dptos.htm

Ureta, S. 2008. Mobilising poverty?: Mobile phone use and everyday spatial mobility among low-income families in Santiago, Chile. The Information Society, 24(2):83-92.

Ward, J. and Peppard, J. 2002. Strategic Planning for Information Systems, $3^{\text {rd }}$ edn. Chichester, UK: John Wiley.

Warschauer, M. 2002. Reconceptualizing the digital divide, First Monday, 7(7). 